\title{
Pengembangan Lembar Kegiatan Mahasiswa Elektronik (e-LKM) berbasis Collaborative Learning OJS Untuk Mata Kuliah Dasar-Dasar Pendidikan MIPA
}

\author{
Fitri Aldresti*, Erviyenni, Sri Haryati \\ Program Studi Pendidikan Kimia, FKIP, Universitas Riau \\ *Email: fitri.aldresti@lecturer.unri.ac.id
}

DOI: https://doi.org/10.33369/pendipa.5.3.292-299

\begin{abstract}
The aim of this study was to develop a collaborative learning-based electronic students activity sheets which is valid for the Education of Mathematic and Basic Natural Science course. This research and development used a 3-D model which adapts the Thiagarajan 4-D development research model. This model consists of three stages, namely: define, design, and develop. A series on collaborative learning based Electronic Students Activity Sheets support college students to be active, interact with each other, and collaborate in the learning process. The results of the development are three activity sheets with different topics. The validation test shows that the Collaborative Learning-based Electronic Students Activity Sheets that has been developed is suitable for use in the Mathematics and Basics Natural Science Education course with a percentage of the validity are $92.36 \%$; $86.11 \%$; and $87.50 \%$ respectively.
\end{abstract}

Keywords: Electronic students activity sheets; mathematic and basic natural science education; collaborative learning.

\begin{abstract}
ABSTRAK
Penelitian ini bertujuan untuk mengembangkan Lembar Kegiatan Mahasiswa Elektronik (e-LKM) berbasis collaborative learning yang valid untuk mata kuliah Dasar-Dasar Pendidikan MIPA. (DDPMIPA). Penelitian pengembangan (Research and Development) ini menggunakan model 3-D (Three D) yang mengadaptasi model penelitian pengembangan 4-D Thiagarajan. Model penelitian dan pengembangan ini terdiri atas tiga tahap, yaitu: define (pendefinisian), design (perancangan), dan develop (pengembangan). Rangkaian aktivitas pada e-LKM berbasis collaborative learning yang mendukung mahasiswa untuk aktif, saling berinteraksi, dan berkolaborasi dalam proses pembelajaran. Hasil pengembangan berupa tiga produk e-LKM dengan topik berbeda. Uji validasi menunjukkan bahwa e-LKM yang telah dikembangkan layak digunakan pada mata kuliah DDPMIPA dengan persentase validitas e-LKM 1 sebesar 92,36\%, e-LKM 2 sebesar $86,11 \%$, dan e-LKM 3 sebesar $87,50 \%$.
\end{abstract}

Kata kunci: E-LKM, DDPMIPA, Pembelajaran kolaborasi.

\section{PENDAHULUAN}

Perkembangan sains dan teknologi yang sangat pesat menuntut tiap individu agar berkompetensi dan mampu bersaing secara global. Penguasaan teknologi dan memahami sains (literasi sains) untuk dapat memecahkan permasalahan yang dihadapi menjadi kompetensi penting yang harus dimiliki individu. Hal ini menjadikan guru IPA sebagai pihak yang turut berperan dalam mewujudkan sumber daya manusia yang berkualitas. IPA berkaitan dengan cara mencari tahu tentang alam secara sistematis, sehingga IPA bukan hanya sekadar penguasaan kumpulan pengetahuan yang berupa fakta-fakta, konsep-konsep, atau prinsip-prinsip saja tetapi juga merupakan suatu proses penemuan (Sumarauw et al., 2017). Hal esensial tersebut yang harus dipahami oleh mahasiswa calon guru sains/IPA.

Di Program Studi Pendidikan Kimia Fakultas Keguruan dan Ilmu Pendidikan Universitas Riau, Dasar-Dasar Pendidikan Matematika dan Ilmu Pengetahuan Alam 
(DDPMIPA) merupakan mata kuliah wajib bagi mahasiswa yang merupakan calon guru sains. Melalui pembelajaran pada mata kuliah DDMIPA, mahasiswa calon guru tidak hanya sekadar menerima informasi tetapi mahasiswa dituntut untuk terlibat dan berpartisipasi aktif agar mampu memahami materi perkuliahan, mengolah, dan mengkomunikasikannya. DDPMIPA merupakan mata kuliah wajib bagi mahasiswa di Prodi Pendidikan Kimia dengan bobot 2 SKS. Kompetensi yang akan diperoleh mahasiswa setelah mengikuti mata kuliah ini adalah mampu memahami hakikat, konsep dan prinsip-prinsip pendidikan IPA, menjelaskan tujuan pendidikan IPA, menjelaskan teori belajar dan penerapan dalam pendidikan IPA, menjelaskan metode dan pendekatan pembelajaran IPA, memahami keterampilan proses dalam pendidikan IPA, menjelaskan faktor yang mempengaruhi pendidikan IPA di sekolah, menganalisis masalah perkembangan pendidikan IPA, dan mengidentifikasi komponen Lembar Kegiatan Peserta Didik (LKPD) dan alat peraga sederhana untuk pembelajaran IPA.

Pada pelaksanaan pembelajaran mata kuliah DDPMIPA, tim pengampu mata kuliah berupaya untuk menyelenggarakan proses pembelajaran berbasis learner centered agar mahasiswa terlibat aktif dalam perkuliahan. Mahasiswa dibagi menjadi beberapa kelompok yang beranggotakan 4-5 orang dalam tiap kelompok. Melalui pembentukan kelompok, mahasiswa dapat saling berdiskusi selama proses perkuliahan agar kompetensi yang diharapkan tercapai secara optimal. Meskipun telah dibentuk dalam kelompok kecil, tidak semua mahasiswa terlibat aktif dalam proses diskusi sehingga dibutuhkan waktu lebih lama dalam menyelesaikan perkuliahan. Akibatnya alokasi waktu untuk mata kuliah DDMIPA selama 2 SKS seringkali tidak cukup untuk menuntaskan materi pembelajaran. Oleh sebab itu, diperlukan perangkat pembelajaran yang dapat mengefektifkan proses pembelajaran dan membantu mahasiswa agar berpartisipasi aktif berkolaborasi selama proses perkuliahan.

Lembar Kegiatan Mahasiswa (LKM) merupakan salah satu perangkat pembelajaran yang didesain untuk membantu mahasiswa/peserta didik dalam mengikuti proses pembelajaran di kelas (Patresia et al., 2020;
Purwati, 2019). LKM mendukung mahasiswa dalam melakukan kegiatan pemecahan masalah (Febriani, 2016; Lestari, 2018). Selain itu, di dalam LKM juga bisa disertakan materi, ringkasan, dan petunjuk pelaksanaan kegiatan pembelajaran (Prastowo, 2015). Oleh sebab itu, pengerjaan LKM oleh mahasiswa selama proses diharapkan dapat membantu mahasiswa untuk berpartisipasi aktif dalam proses perkuliahan. LKM dapat mendukung mahasiswa untuk membangun konsep materi yang dipelajari dengan lebih aktif berpikir dan melakukan kegiatan.

Fenomena teknologi yang berkembang begitu pesat juga dapat mendatangkan manfaat dalam bidang pendidikan. Media elektronik termasuk salah satu perangkat teknologi yang dapat digunakan dalam proses pembelajaran. LKM dalam bentuk elektronik berupa e-LKM dapat menjadi suatu terobosan untuk mewujudkan proses pembelajaran yang lebih praktis dan efisien. Berbagai keunggulan LKM dalam bentuk digital seperti praktis, mudah diakses, dan tidak membutuhkan biaya besar menjadikannya sebagai bentuk inovasi bagi dosen pengajar dalam memfasilitasi mahasiswa agar dapat terlibat aktif dalam proses pembelajaran.

Penyusunan perangkat pembelajaran seperti e-LKM sebaiknya menyesuaikan dengan strategi perkuliahan yang diterapkan di kelas. Salah satu pendekatan pembelajaran yang menjadikan mahasiswa sebagai pusat pembelajaran adalah collaborative learning. Collaborative learning atau pembelajaran kolaboratif dapat digambarkan sebagai proses interaksi dalam kelompok kecil di mana beberapa orang saling membantu untuk mencapai tujuan secara kolektif (Laal et al., 2013). Aktivitas dalam pembelajaran kolaboratif sangat luas, tetapi lebih terpusat pada aktivitas peserta didik dalam mengeksplorasi atau mengembangkan aplikasi konten pembelajaran untuk mengembangkan penalaran, mempraktikkan penggunaan keterampilan berpikir tingkat tinggi, dan merumuskan pengetahuan (Barkley et al., 2014). Dalam proses pembelajaran mahasiswa sebagai peserta didik berkolaborasi dalam kelompok untuk mengidentifikasi informasi, untuk mengangkat masalah, menyusun hipotesis, untuk mengumpulkan informasi dari sumber, untuk 
memberikan solusi alternatif dan menuliskan kesimpulan berdasarkan semua jawaban (Wiyarsi et al., 2015). Keunggulan pembelajaran kolaboratif adalah dapat meningkatkan prestasi belajar, meningkatkan kepercayaan diri, proses pembelajaran yang menyenangkan, dan mengembangkan keterampilan sosial peserta didik (Barkley et al., 2014; Scager et al., 2016; Zhang \& Cui, 2018). Setiap mahasiswa mendapat kesempatan yang sama untuk berbagi pendapat, ide, gagasan, sikap, dan pengalaman untuk memecahkan permasalahan (Amania \& Rasid Achmadi, 2019).

E-LKM berbasis collaborative learning yang disusun berisikan petunjuk dan pertanyaan yang mengarahkan mahasiswa untuk mengkonstruk konsep materi dalam mata kuliah DDPMIPA. E-LKM disusun menyesuaikan tahapan pembelajaran kolaborasi yang berpusat pada mahasiswa. Tahapan dalam pembelajaran kolaborasi yang tertuang di dalam e-LKM terdiri atas:

\section{1) Pendahuluan}

Pada tahap awal ini mahasiswa diberikan motivasi untuk memunculkan minat, mendorong rasa ingin tahu, menggali pemahaman yang telah dimiliki oleh mahasiswa sebelumnya terkait materi yang akan dipelajari, dan mengidentifikasi permasalahan yang akan dipecahkan.

2) Eksplorasi

Pada tahap eksplorasi mahasiswa saling bersinergi mengumpulkan informasi dan data terkait permasalahan yang telah teridentifikasi.

3) Kolaborasi

Dalam tahap kolaborasi, setiap mahasiswa dalam kelompok kolaboratif bekerja secara bersinergi untuk menganalisis dan memformulasikan jawaban atas permasalahan yang didiskusikan. Selanjutnya hasil kerja kelompok dipresentasikan untuk dikaji bersama.

4) Kesimpulan

Mahasiswa menarik kesimpulan dari hasil diskusi yang telah dilakukan.

Dalam tiap tahapannya memungkinkan mahasiswa untuk saling berinteraksi dalam setiap prosesnya (Ajayi \& Ajayi, 2020; Apriono, 2013; Aziz et al., 2013). Berdasarkan hasil penelitian terdahulu diketahui bahwa penggunaan lembar kegiatan berbasis pembelajaran kolaboratif dapat meningkatkan aktivitas belajar dan meningkatkan hasil belajar mahasiswa (Aziz et al., 2013; Marisda \& Handayani, 2020). Berdasarkan paparan di atas maka pelaksanaan penelitian pengembangan ini bertujuan untuk mengembangkan LKM dalam bentuk digital berbasis collaborative learning untuk mata kuliah DDPMIPA.

\section{METODE PENELITIAN}

Penelitian pengembangan (Research and Development) ini menggunakan model 3-D (Three D) yang mengadaptasi model penelitian pengembangan 4-D Thiagarajan (Trianto, 2010). Metode penelitian dan pengembangan yang dilakukan terdiri atas tiga tahap, yaitu: define (pendefinisian), design (perancangan), develop (pengembangan).

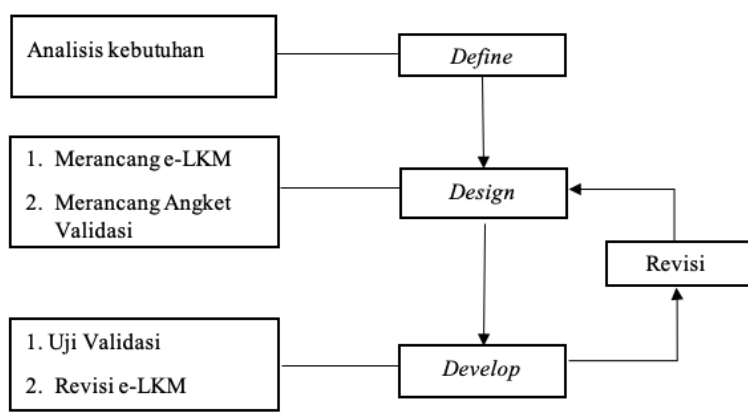

Gambar 1. Tahapan Model Penelitian Pengembangan e-LKM berbasis Collaborative Learning untuk mata kuliah DDPMIPA

Penelitian dan pengembangan dilakukan di Prodi Pendidikan Kimia, FKIP, Universitas Riau. Instrumen penelitian yang digunakan adalah lembar validasi e-LKM berbasis Collaborative Learning. Uji validasi produk e-LKM dilakukan oleh dua orang dosen ahli. Pada spesifikasi produk dijabarkan bahwa validitas e-LKM berbasis Collaborative Learning dilihat dari aspek kelayakan isi, kelayakan karakteristik eLKM berbasis Collaborative Learning, kelayakan kebahasaan, dan kelayakan kegrafisan sebagaimana disajikan dalam Tabel 1.

Interpretasi skor hasil validasi ahli terhadap e-LKM yang dikembangkan disajikan pada tabel 2. Data hasil penelitian dari proses pengembangan e-LKM berbasis collaborative learning untuk mata kuliah DDPMIPA dianalisis secara deskriptif. Analisis keterbacaan e-LKM diperoleh dari hasil uji coba terbatas pada 
mahasiswa yang telah menempuh mata kuliah DDPMIPA.

Tabel 1. Indikator Penilaian Validitas eLKM berbasis Collaborative Learning

\section{No.}

\section{Indikator Penilaian}

\begin{tabular}{|c|c|}
\hline & Kelayakan Isi \\
\hline 1 & $\begin{array}{l}\text { Kesesuaian e-LKM dengan } \\
\text { Capaian Pembelajaran Mata } \\
\text { Kuliah (CPMK). }\end{array}$ \\
\hline 2 & $\begin{array}{l}\text { e-LKM sesuai dengan Tujuan (sub-CPMK) } \\
\text { yang akan dicapai. }\end{array}$ \\
\hline 3 & e-LKM sesuai dengan subtansi materi. \\
\hline \multirow[t]{2}{*}{4} & $\begin{array}{l}\text { e-LKM sesuai dengan kebutuhan bahan } \\
\text { ajar mahasiswa. }\end{array}$ \\
\hline & $\begin{array}{l}\text { Kelayakan Karakteristik e-LKM } \\
\text { berbasis Collaborative Learning }\end{array}$ \\
\hline \multirow[t]{3}{*}{5.} & $\begin{array}{l}\text { e-LKM mendorong mahasiswa untuk } \\
\text { berkolaborasi. } \\
\text { e-LKM mendorong mahasiswa untuk }\end{array}$ \\
\hline & $\begin{array}{l}\text { berpartisipasi aktif dalam proses } \\
\text { perkuliahan. }\end{array}$ \\
\hline & Kelayakan Kebahasaan \\
\hline 7. & $\begin{array}{l}\text { Bahasa yang digunakan dapat dipahami } \\
\text { mahasiswa. }\end{array}$ \\
\hline 8. & $\begin{array}{l}\text { e-LKM menggunakan struktur kalimat } \\
\text { yang jelas. }\end{array}$ \\
\hline 9. & $\begin{array}{l}\text { e-LKM konsisten dalam penggunaan istilah } \\
\text { dan singkatan. }\end{array}$ \\
\hline 10. & $\begin{array}{l}\text { e-LKM sesuai dengan kaidah Bahasa } \\
\text { Indonesia yang baik dan } \\
\text { benar. }\end{array}$ \\
\hline
\end{tabular}

11. Kelengkapan sistematika penyajian e-LKM (Judul, petunjuk e-LKM, instruksi kegiatan mahasiswa, dan evaluasi)

12. Kejelasan tulisan dan gambar pada e-LKM

13. e-LKM menyediakan ruang yang cukup untuk memberi keleluasaan bagi mahasiswa untuk menulis maupun menggambarkan hal-hal yang ingin disampaikan oleh mahasiswa.

14. e-LKM mudah diakses mahasiswa. Kelayakan Kegrafisan
15. e-LKM menggunakan jenis dan ukuran huruf yang baik dan menarik

16. e-LKM memiliki tata letak (lay out) yang menarik

17. e-LKM menggunakan ilustrasi/gambar/foto/video yang baik dan berhubungan dengan konsep

18. e-LKM memiliki desain tampilan yang menarik

Tabel 2. Indikator Kriteria Validitas Produk e-LKM

\begin{tabular}{cc}
\hline Presentase (\%) & Validitas \\
\hline $0-20$ & Sangat rendah \\
$21-40$ & Rendah \\
$41-60$ & Sedang \\
$61-80$ & Tinggi \\
$81-100$ & Sangat Tinggi \\
\hline
\end{tabular}

(Adaptasi dari Landis \& Koch, 1977)

\section{HASIL DAN PEMBAHASAN}

Proses pengembangan e-LKM berbasis Collaborative Learning untuk mata kuliah DDPMIPA secara garis besar terdiri atas tiga tahap, yaitu define, design, dan develop. Hasil dari setiap tahapan penyusunan e-LKM dideskripsikan sebagai berikut:

Define (Pendefinisian)

Tahap define merupakan tahap awal dalam prosedur pengembangan yang mencakup semua kegiatan pengumpulan data untuk analisis kebutuhan. Dalam pengembangan e-LKM ini, tahapan define diawali dengan menganalisis permasalahan pada mata kuliah DDPMIPA, yaitu belum adanya lembar kegiatan mahasiswa yang dapat mendukung partisipasi aktif mahasiswa selama proses pembelajaran. Selanjutnya menspesifikasikan capaian pembelajaran (specifying instructional objectives) yang akan dikembangkan e-LKMnya dan melakukan analisis konsep (concept analysis) yang akan disajikan, termasuk menyusun langkah-langkah yang akan dilakukan secara rasional. Pada tahap ini juga dilakukan analisis mahasiswa untuk mengetahui karakteristik mahasiswa yang mengikuti mata kuliah DDPMIPA. Adapun mahasiswa yang mengikuti kelas DDPMIPA adalah mahasiswa tahun pertama Prodi Pendidikan Kimia. Dari analisis kebutuhan yang 
dilakukan maka dirancang tiga e-LKM dengan topik: 1) Keterampilan Proses Sains; 2) Faktor Kreativitas Guru dalam Pembelajaran IPA; dan 3) Lembar Kegiatan Peserta Didik (LKPD) dalam Pembelajaran IPA.

\section{Design (Perancangan)}

Pada tahap perancangan dilakukan penyusunan e-LKM yang memenuhi syarat. Perancangan e-LKM dilakukan sesuai dengan hasil analisis kebutuhan pada tahap define. Format e-LKM yang dirancang terdiri atas : 1) judul; 2) identitas mahasiswa; c) petunjuk pengerjaan; d) tujuan; e) bahan kajian, f) aktivitas pembelajaran; e) evaluasi; f) daftar referensi. Tampilan judul e-LKM 1 dapat dilihat pada Gambar 2. Cuplikan aktivitas pembelajaran berupa kegiatan pendahuluan dapat dilihat pada Gambar 3.
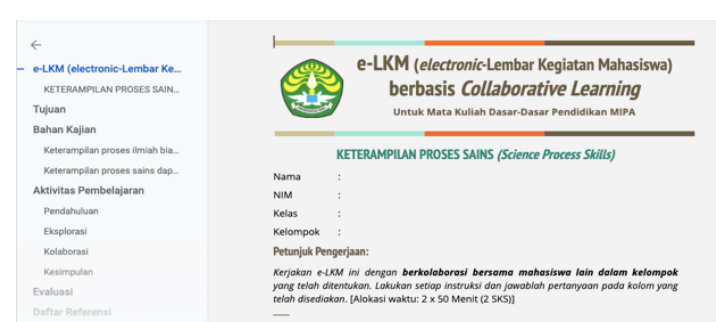

Gambar 2. Tampilan Judul pada e-LKM 1

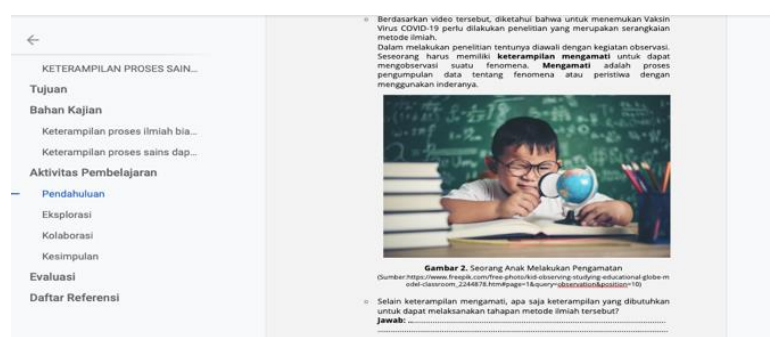

Gambar 3. Kegiatan Pendahuluan pada e-LKM 1

\begin{abstract}
Aktivitas pembelajaran dalam e-LKM dirancang berdasarkan karakteristik pembelajaran kolaboratif, yaitu pendahuluan (identifikasi masalah), eksplorasi, kolaborasi, dan penarikan kesimpulan. Penyusunan kegiatan pembelajaran disesuaikan dengan paradigma yang mendasari kegiatan pembelajaran kolaboratif, yaitu belajar aktif dan mandiri, melibatkan peserta didik dalam permasalahan yang konteksnya telah dikenali, perbedaan karakter peserta didik, dan proses sosial dalam belajar (Marisda \& Handayani, 2020; Micari \&
\end{abstract}

Pazos, 2020; Purnamawati \& Jaya, 2016). Selama proses pembelajaran kolaboratif dengan menggunakan e-LKM dosen dapat melaksanakan tugas sebagai fasilitator, pembimbing, dan mediator yang baik (Astutik \& Prahani, 2018).

e-LKM dibuat menggunakan aplikasi Google Docs. Aplikasi ini merupakan layanan berbasis web milik Google yang memungkinkan pengguna untuk melakukan pekerjaan dengan berkolaborasi bersama pengguna lain secara real time. Selain pengembangan e-LKM, lembar validasi juga dirancang untuk menilai validitas eLKM yang telah dirancang.

\section{Develop (Pengembangan)}

Tahap pengembangan terbagi menjadi dua kegiatan, yaitu: expert appraisal dan development testing. Expert appraisal merupakan tahap memvalidasi atau menilai kelayakan rancangan produk e-LKM. Validasi dilakukan oleh ahli dalam bidangnya. Saransaran yang diberikan selanjutnya digunakan untuk memperbaiki rancangan produk yang telah disusun. Development testing merupakan tahap uji coba rancangan produk pada sasaran subjek. Uji coba yang dilakukan bersifat terbatas guna mengumpulkan komentar dari mahasiswa pengguna e-LKM. Selanjutnya rancangan eLKM diperbaiki agar memperoleh hasil yang efektif.

Kualitas produk pengembangan pembelajaran harus memenuhi kriteria valid. ELKM yang dirancang ditelaah terlebih dahulu untuk mengetahui kekurangan dan hal-hal yang perlu diperbaiki. Selanjutnya e-LKM yang telah direvisi dilakukan analisis kelayakan. Terdapat empat aspek yang dianalisis meliputi: kelayakan isi, kelayakan karakteristik e-LKM berbasis Collaborative Learning, kelayakan kebahasaan, dan kelayakan kegrafisan. Hasil analisis lembar validasi e-LKM berbasis Collaborative Learning disajikan pada Tabel 3. Untuk analisis hasil validasi ditinjau dari tiap aspek indikator penilaian dapat dilihat pada Tabel 4.

Tabel 3. Persentase Skor Validitas Produk e-LKM

\begin{tabular}{cc}
\hline $\begin{array}{c}\text { e-LKM Mata } \\
\text { Kuliah } \\
\text { DDPMIPA }\end{array}$ & $\begin{array}{c}\text { Presentase Skor } \\
(\boldsymbol{\%})\end{array}$ \\
\hline e-LKM 1. & $92,36 \%$ \\
\hline
\end{tabular}




\begin{tabular}{ll}
\hline $\begin{array}{l}\text { Keterampilan } \\
\text { Proses Sains }\end{array}$ & \\
\hline e-LKM 2. Faktor & \\
$\begin{array}{l}\text { Kreativitas Guru } \\
\text { dalam }\end{array}$ & \\
Pembelajaran & $86,11 \%$ \\
IPA & \\
\hline e-LKM 3. LKPD & \\
dalam & \\
Pembelajaran & $87,50 \%$ \\
IPA & \\
\hline
\end{tabular}

Tabel 4. Analisis Hasil Validasi e-LKM per Indikator Penilaian

\begin{tabular}{lccc}
\hline $\begin{array}{l}\text { Indikator } \\
\text { Penilaian }\end{array}$ & $\begin{array}{c}\text { e-LKM } \\
\mathbf{1}\end{array}$ & $\begin{array}{c}\text { e-LKM } \\
\mathbf{2}\end{array}$ & $\begin{array}{c}\text { e-LKM } \\
\mathbf{3}\end{array}$ \\
\hline Kelayakan isi & $93,75 \%$ & $84,37 \%$ & $90,63 \%$ \\
\hline $\begin{array}{l}\text { Kelayakan } \\
\text { Karakteristik } \\
\text { e-LKM } \\
\text { berbasis } \\
\begin{array}{l}\text { Collaborative } \\
\text { Learning }\end{array}\end{array}$ & $87,5 \%$ & $81,25 \%$ & $81,25 \%$ \\
\hline $\begin{array}{l}\text { Kelayakan } \\
\text { Kebahasaan }\end{array}$ & $93,75 \%$ & $87,50 \%$ & $93,75 \%$ \\
\hline $\begin{array}{l}\text { Kelayakan } \\
\text { Penyajian }\end{array}$ & $87,5 \%$ & $78,12 \%$ & $75 \%$ \\
\hline $\begin{array}{l}\text { Kelayakan } \\
\text { Kegrafisan }\end{array}$ & $96,88 \%$ & $100 \%$ & $93 \%$ \\
\hline
\end{tabular}

Hasil uji validasi pada Tabel 3 menunjukkan bahwa ketiga e-LKM yang dikembangkan valid dan layak untuk diterapkan pada perkuliahan DDPMIPA. Selanjutnya pada hasil analisis lanjutan di Tabel 4 terlihat bahwa aspek kelayakan penyajian pada e-LKM 2 dan e-LKM 3 memperoleh presentase terendah, yaitu sebesar $78,12 \%$ dan $75 \%$. Dari saran yang diberikan oleh validator pada lembar validasi diketahui bahwa dibutuhkan ruang yang lebih luas untuk kolom jawaban di dalam e-LKM. Selain itu terdapat instruksi yang kurang tegas pada kedua e-LKM tersebut. Selanjutnya dilakukan perbaikan agar instruksi dalam e-LKM yang dirancang lebih jelas dan rasional.

Selain uji validitas oleh validator ahli, dilakukan juga uji keterbacaan e-LKM oleh mahasiswa yang telah menempuh mata kuliah DDPMIPA. Dari uji tersebut diperoleh beberapa saran terkait konsistensi penggunaan istilah di dalam e-LKM. Sebaiknya kata-kata istilah yang digunakan dalam e-LKM tidak berubah-ubah agar lebih mudah dipahami oleh mahasiswa. Berdasarkan komentar yang disampaikan mahasiswa diketahui bahwa e-LKM yang dirancang berisi kegiatan pembelajaran yang runtut, jelas, dengan tampilan yang menarik.

Dari hasil validasi diketahui bahwa e-LKM yang dikembangkan sudah mencakup hal-hal berikut:

1. e-LKM sudah sesuai dengan capaian pembelajaran yang menjadi tujuan pembelajaran. Aktivitas yang dirancang telah mengarah pada pencapaian tujuan pembelajaran yang ditetapkan. Setelah mengerjakan e-LKM mahasiswa diharapkan dapat menuntaskan capaian pembelajaran pada mata kuliah DDPMIPA.

2. e-LKM memuat aktivitas pembelajaran yang sesuai dengan karakteristik collaborative learning. Permasalahan yang disajikan dalam pembelajaran collaborative learning mendukung mahasiswa untuk saling berinteraksi dan mengaktifkan mahasiswa dalam proses pembelajaran (Marisda \& Handayani, 2020; Wang et al., 2020). Oleh sebab itu, kegiatan pembelajaran harus berpusat pada mahasiswa dan dalam melaksanakan pembelajaran berbasis collaborative learning dosen berperan sebagai fasilitator.

3. e-LKM memuat instruksi dan pertanyaan yang rasional dan dapat dipahami oleh mahasiswa. Sebagai bahan ajar yang mengarahkan mahasiswa dalam mencapai tujuan pembelajaran, e-LKM yang dikembangkan berisi instruksi dan pertanyaannya yang membimbing dan memandu mahasiswa mulai dari merumuskan permasalahan, mengumpulkan informasi, berdiskusi, dan menyimpulkan (Watika, 2019).

4. e-LKM dilengkapi dengan bahan kajian, fitur dan desain yang menarik, serta dengan tata letak yang memudahkan mahasiswa untuk mengerjakannya. Kemudahan mahasiswa dalam mengerjakan e-LKM adalah hal penting yang perlu diperhatikan. e-LKM berbasis web yang dikembangkan menggunakan aplikasi Google Docs ini mendukung proses collaborative learning (Nuswowati et al., 2019). Fitur dari aplikasi ini memberikan kesempatan kepada mahasiswa untuk dapat berdiskusi, 
berkolaborasi, sekaligus mengerjakan secara bersamaan e-LKM melalui perangkat masingmasing sehingga setiap mahasiswa dapat berpartisipasi aktif (Abrams, 2019; Saeed \& Al Qunayeer, 2020).

\section{KESIMPULAN}

Berdasarkan hasil penelitian dan pengembangan dihasilkan produk e-LKM berbasis collaborative learning untuk mata kuliah DDPMIPA yang dikembangkan dengan model pengembangan 3D. Hasil analisis uji validasi diketahui bahwa ketiga e-LKM berbasis collaborative learning yang telah dikembangkan ada pada kategori "valid" sehingga layak digunakan pada mata kuliah DDPMIPA. Validitas e-LKM dilihat dari aspek kelayakan isi, kelayakan karakteristik e-LKM berbasis Collaborative Learning, kelayakan kebahasaan, dan kelayakan kegrafisan. Uji validasi menunjukkan presentase validitas e-LKM 1 sebesar 92,36\%, e-LKM 2 sebesar 86,11\%, dan e-LKM 3 sebesar 87,50\%.

\section{DAFTAR PUSTAKA}

Abrams, Z. I. (2019). Collaborative Writing and Text Quality in Google Docs. Language Learning \& Technology, 23(2), 22-42.

Ajayi, P. O., \& Ajayi, L. F. (2020). Use of Online Collaborative Learning Strategy in Enhancing Postgraduates Learning Outcomes In Science Education. Educational Research and Reviews, 15(8), 504-510.

Amania, I., \& Rasid Achmadi, H. (2019). Penerapan Pembelajaran Kolaboratif Dengan Menggunakan Model Pembelajaran Diskusi Terhadap Hasil Belajar Fisika. Inovasi Pendidikan Fisika, $8(2)$.

Apriono, D. (2013). PEMBELAJARAN KOLABORATIF: Suatu Landasan untuk Membangun Kebersamaan dan Keterampilan. Diklus, 17(1).

Astutik, S., \& Prahani, B. K. (2018). The Practicality and Effectiveness of Collaborative Creativity Learning (CCL) Model by Using PhET Simulation to Increase Students' Scientific Creativity.
International Journal of Instruction, 11(4), 409-424.

Aziz, A., Adnan, A., Taiyeb, A., \& Faisal, M. (2013). Penerapan Pembelajaran Kolaboratif untuk Meningkatkan Aktifitas Belajar Siswa Kelas XI IPA 3 Melalui Lesson Study Berbasis Sekolah di SMA N 8 Makassar. Jurnal Kajian Dan Penelitian Biologi, 14(1), 38-43.

Barkley, E. F., Cross, K. P., \& Major, C. H. (2014). Collaborative learning techniques: A handbook for college faculty. John Wiley \& Sons.

Febriani, M. (2016). Pemanfaatan Lembar Kerja Mahasiswa Untuk Meningkatkan Keaktifan Mahasiswa: Studi Penerapan Lesson Study Pada Mata Kuliah Buku Teks Pelajaran Bahasa Indonesia. Jurnal Pendidikan Bahasa Dan Sastra UPI, 16(2), 203-212.

Laal, M., Geranpaye, L., \& Daemi, M. (2013). Individual accountability in collaborative learning. Procedia-Social and Behavioral Sciences, 93, 286-289.

Lestari, N. (2018). Prosedural Mengadopsi Model 4D dari Thiagarajan Suatu Studi Pengembangan LKM Bioteknologi Menggunakan Model PBL bagi Mahasiswa. Jurnal Teknologi, 1(1), 56-65.

Marisda, D. H., \& Handayani, Y. (2020). Model Pembelajaran Kolaboratif Berbasis Tugas Sebagai Alternatif Pembelajaran Fisika Matematika. Prosiding Seminar Nasional Fisika PPs Universitas Negeri Makassar, 2, 9-12.

Micari, M., \& Pazos, P. (2020). Beyond Grades: Improving College Students' Social-Cognitive Outcomes in STEM through a Collaborative Learning Environment. Learning Environments Research, 1-14.

Nuswowati, M., Amalina, N. D., Kadarwati, S., Harjito, H., \& Susilaningsih, E. (2019). Pemanfaatan Aplikasi Google dalam Pembelajaran Kolaboratif. Rekayasa: Jurnal Penerapan Teknologi Dan Pembelajaran, 17(1), 30-34.

Patresia, I., Silitonga, M., \& Ginting, A. (2020). Developing Biology Students' Worksheet based on STEAM to Empower Science 
Process Skills. JPBI (Jurnal Pendidikan Biologi Indonesia), 6(1), 147-156.

Prastowo, A. A. (2015). Panduan Kreatif Membuat Bahan Ajar Inovatif. Jogjakarta: Diva Press.

Purnamawati, P., \& Jaya, H. (2016). Pengembangan Model Pembelajaran Kolaboratif Melalui Pendekatan CSCL (Computer Supported Collaborative Learning) pada Fakultas Teknik Universitas Negeri Makassar. Jurnal MEKOM (Media Komunikasi Pendidikan Kejuruan), 3(2).

Purwati, N. K. R. (2019). Development of Student Worksheet based on Collaborative Learning Model in Learning Course of Numerical Methods. Journal of Physics: Conference Series, 1321(3), 32073.

Saeed, M. A., \& Al Qunayeer, H. S. (2020). Exploring teacher interactive e-feedback on students' writing through Google Docs: factors promoting interactivity and potential for learning. The Language Learning Journal, 1-18.

Scager, K., Boonstra, J., Peeters, T., Vulperhorst, J., \& Wiegant, F. (2016). Collaborative learning in higher education: Evoking positive interdependence. $C B E-$ Life Sciences Education, 15(4), ar69.

Sumarauw, J. M., Ibrahim, M., \& Prastowo, T. (2017). Pengembangan Perangkat Pembelajaran Berbasis Inkuiri Terbimbing Berbantuan Simulasi PhET dalam Pembelajaran IPA. Jurnal Penelitian Pendidikan, 34(1), 25-36.
Trianto, M. P. (2010). Mendesain Model Pembelajaran Inovatif-Progresif: Konsep, Landasan dan Implementasinya pada kurikulum Tingkat Satuan Pendidikan (KTSP). Jakarta: Kencana.

Wang, C., Ma, Y., \& Wu, F. (2020). Comparative Learning Performance and Mental Involvement in Collaborative Inquiry Learning: Three Modalities of Using Virtual Lever Manipulative. Journal of Science Education and Technology, 110.

Watika, L. (2019). Validitas Lembar Kerja Peserta Didik (LKPD) berbasis Collaborative Learning pada Materi Gerak Lurus di Sma Negeri 1 Driyorejo. Inovasi Pendidikan Fisika, 8(2).

Wiyarsi, A., Hendayana, S., Firman, H., \& Anwar, S. (2015). Collaborative Learning to Improve Preservice Teachers' Knowledge About Chemistry Content in the Automotive Vocational Context. Cakrawala Pendidikan, 3, 77353.

Zhang, J., \& Cui, Q. (2018). Collaborative learning in higher nursing education: A systematic review. Journal of Professional Nursing, 34(5), 378 